\title{
Hyalinised hepatic haemangioma mimicking malignancy: an incidental finding
}

\author{
Rinkey Chaudhary, ${ }^{1}$ Tapendra Tiwari, ${ }^{2}$ Rajaram Sharma 지 , 2,3 Saurabh Goyal ${ }^{2}$
}

${ }^{1}$ Radio-diagnosis, Pacific Institute of Medical Sciences, Udaipur, Rajasthan, India ${ }^{2}$ Radio-diagnosis, Pacific Institute of Medical Sciences Umarda Campus, Udaipur, India ${ }^{3}$ Radio-diagnosis, Seth GS Medical College and KEM Hospital, Mumbai, India

\section{Correspondence to} Dr Rajaram Sharma; hemantgalaria13@gmail.com

Accepted 13 February 2022

\section{DESCRIPTION}

Haemangioma is the most common benign hepatic tumour of the liver; despite being common, sclerosing haemangioma is a rare entity with a female predominance. ${ }^{1}$ Based on their imaging features, an atypical haemangioma can be distinguishable from malignancy. Factors responsible for haemangioma degeneration are increased degree of fibrosis, scar formation and thrombosis of its vascular channels, which is called a sclerosing or hyalinising haemangioma, which can lead to its end stage where it is completely sclerosed or hyalinised. ${ }^{2}{ }^{3}$ These sclerosing haemangiomas are asymptomatic and are therefore often incidentally found. The process of sclerosis changes the radiologic characteristics of these haemangiomas. Subsequently, it renders their reliable diagnosis using only imaging characteristics nearly impossible as sclerosing haemangiomas have an imaging appearance that makes them indistinguishable from malignancy, such as metastasis, hepatocellular carcinoma or cholangiocarcinoma. CT is characterised by a lack of early enhancement on dynamic contrast-enhanced CT images and may or may not demonstrate degrees of peripheral enhancement in the late phase; thus, it is difficult to definitively differentiate hyalinised haemangioma from malignant hepatic tumours. ${ }^{4}$ The surgical approach for resection of hepatic

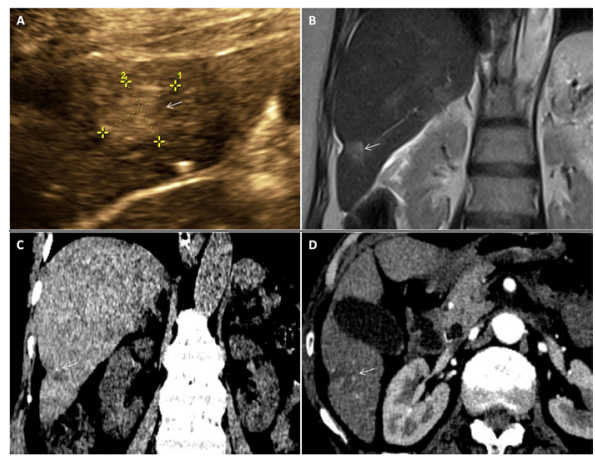

Figure 1 (A) Ultrasonography image, craniocaudal view, at midaxillary line demonstrates an irregular margined hyperechoic lesion in segment $\mathrm{VI}$ of the liver (white arrow). (B) Magnetic resonance cholangiopancreatography, coronal image, T2-weighted image demonstrate an ill-defined hyperintense lesion with adjacent capsule retraction (white arrow). $(C, D)$ Triple-phase contrast-enhanced CT, non-contract coronal and arterial phase axial images, respectively, demonstrate an ill-defined hypodense lesion in C and subtle peripheral nodular enhancement of the lesion in D marked as a white arrow. Adjacent hepatic capsular retraction is evident.

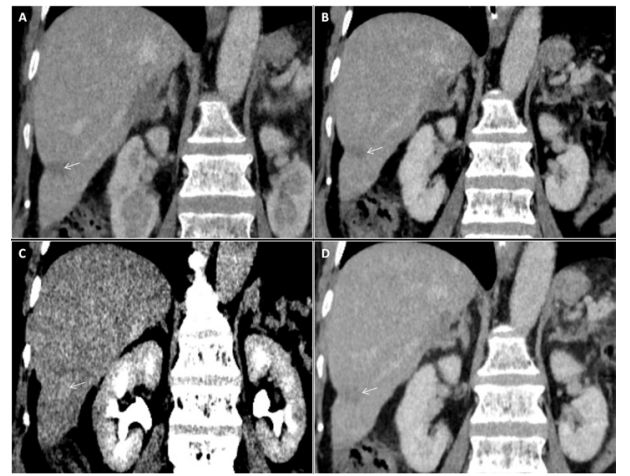

Figure 2 Triple-phase contrast-enhanced CT (CECT) of the abdomen $(\mathrm{A}-\mathrm{C})$ coronal images, portal, venous and equilibrium phase, respectively, demonstrate progressive centripetal filling of the lesion with a relatively isodense appearance in the equilibrium phase (white arrow) suggest a diagnosis of the hepatic haemangioma. (D) CECT of the abdomen, the coronal image in venous phase demonstrate significant capsular depression suggestive of degenerative changes in the adjacent lesion suggestive of sclerosis.

sclerosing haemangioma is controversial. Most of the previously reported tumours were resected due to preoperative misdiagnosis as hepatic malignancies. Percutaneous needle biopsy is not considered adequate because of the possibility of disseminating cancer cells if the tumour is malignant.

A woman in her 60s came to the emergency with a complaint ofreported upper abdominal pain and vomiting for the past few days. Her physical examination shows no localised sign of pathology. Vitals were unremarkable, and the patient was conscious of time, place and person. The patient

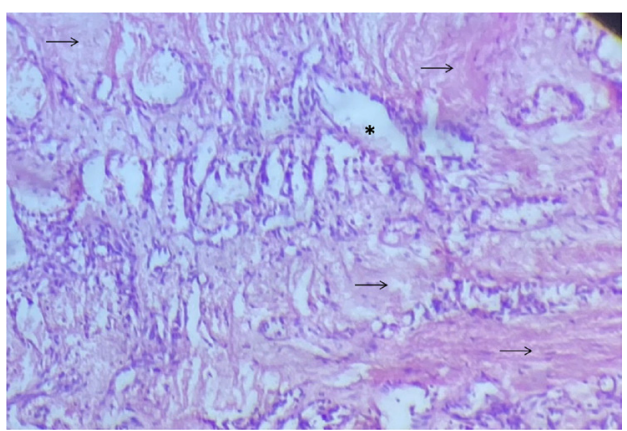

Figure 3 Histopathology image of the liver lesion ( $\times 40)$ demonstrating abundant sclerotic stroma (black arrow) and compressed vascular outlines marked as asterisk, suggestive of benign lesion (hyalinised hepatic haemangioma). 
was admitted to the hospital for further evaluation. Liver function test demonstrated raised serum aspartate aminotransferase (49 IU/L), alanine aminotransferase (56 IU/L) and gammaglutamyl transferase levels (151 IU/L). Serum tumour markers, including alpha-fetoprotein and PIVKA-II, were within normal limits. Serologic tests for hepatitis B and hepatitis C virus were negative. Complete blood count revealed low haemoglobin. The patient was further advised for ultrasonography, which revealed an irregular heterogeneously hyperechoic lesion in the segment VI with retraction of the hepatic surface (figure 1A). Magnetic resonance cholangiopancreatography (MRCP) was advised to further characterise the lesion, which showed a small, ill-defined abnormal T2-hyperintense lesion in segment VI of the liver with adjacent capsular retraction (figure 1B). Based on the ultrasonography (USG) and MRCP, differential diagnosis of cholangiocarcinoma and haemangioma was made. Triple-phase contrast-enhanced CT of the abdomen and the pelvis showed an ill-defined hypodense lesion in segment VI with subtle peripheral nodular enhancement on arterial phase with progressive centripetal contrast filling became isodense to surrounding liver parenchyma on delayed phase (figures 1C, D and 2). Capsular

\section{Learning points}

Due to variable degrees of degeneration, hyalinised hepatic haemangioma can mimic hepatic malignancy.

- Triple-phase contrast-enhanced CT remains best noninvasive imaging modality to diagnose hyalinised hepatic haemangioma and unnecessary interventions can be avoided.

- Biopsy and histopathological examination remains the gold standard to confirm the hyalinised hepatic haemangioma. retraction was evident; however, no obvious focal dilatation of the intrahepatic biliary radicals was noted. Based on these findings, diagnosis of benign hepatic haemangioma was made. The lesion was biopsied and sent for histopathological examination. Histopathological examination revealed dense stroma surrounding the obliterated and compressed vessels. Endothelial cell outline and obliterated lumen was also seen (figure 3 ). Thus, the diagnosis of the hyalinised hepatic haemangioma was made. The patient was assured about the benign nature of the lesion.

Contributors RC and TT contributed to the planning, conduct, reporting, conception and design, acquisition of data, or analysis and interpretation of data. RS and SG contributed to the acquisition of data and interpretation of data.

Funding The authors have not declared a specific grant for this research from any funding agency in the public, commercial or not-for-profit sectors.

Competing interests None declared.

Patient consent for publication Consent obtained directly from patient(s)

Provenance and peer review Not commissioned; externally peer reviewed.

Case reports provide a valuable learning resource for the scientific community and can indicate areas of interest for future research. They should not be used in isolation to guide treatment choices or public health policy.

\section{ORCID iD}

Rajaram Sharma http://orcid.org/0000-0003-1126-5875

\section{REFERENCES}

1 Semelka RC, Sofka CM. Hepatic hemangiomas. Magn Reson Imaging Clin N Am 1997;5:241-53

2 Cheng HC, Tsai SH, Chiang JH, et al. Hyalinized liver hemangioma mimicking malignant tumor at MR imaging. AJR Am J Roentgenol 1995;165:1016-7.

3 Song JS, Kim YN, Moon WS. A sclerosing hemangioma of the liver. Clin Mol Hepatol 2013;19:426-30.

4 Doyle DJ, Khalili K, Guindi M, et al. Imaging features of sclerosed hemangioma. AJR Am J Roentgenol 2007;189:67-72.

Copyright 2022 BMJ Publishing Group. All rights reserved. For permission to reuse any of this content visit

https://www.bmj.com/company/products-services/rights-and-licensing/permissions/

BMJ Case Report Fellows may re-use this article for personal use and teaching without any further permission.

Become a Fellow of BMJ Case Reports today and you can:

- Submit as many cases as you like

- Enjoy fast sympathetic peer review and rapid publication of accepted articles

- Access all the published articles

- Re-use any of the published material for personal use and teaching without further permission

Customer Service

If you have any further queries about your subscription, please contact our customer services team on +44 (0) 2071111105 or via email at support@bmj.com.

Visit casereports.bmj.com for more articles like this and to become a Fellow 